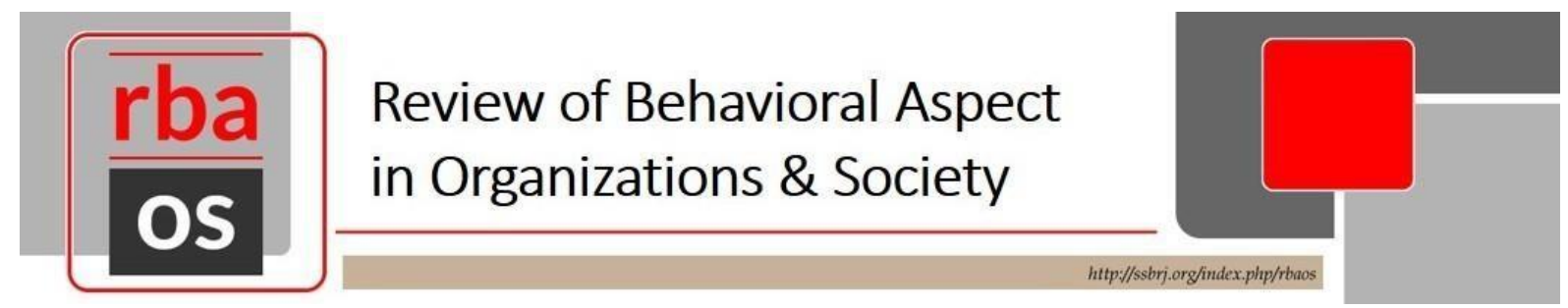

\title{
SURVIVAL PLAN FOR JAPANESE LADIES FASHION IN AGING SOCIETY OF JAPAN
}

\author{
Noriyuki Suyama, Bunka Gakuen University, Japan
}

\begin{abstract}
There are many obstacles to establishing successful international business relations, and many fashion industries are still in the process of building reputations outside of the country. Language barriers, differences in governmental policies and regulations, and insufficient market information are all significant obstructions. Thus, currently the main challenges of the Japanese fashion industry are to adapt its products and distribution methods to the changing demographic of an aging domestic population, and to expand and secure its international markets. On the other hands, the aging of Japan is thought to outweigh all other nations, with Japan being purported to have the highest proportion of elderly citizens. In 2014, people aged 65 and older in Japan make up a quarter of its total population, estimated to reach a third by 2050. The dramatic aging of Japanese society as a result of sub-replacement fertility rates and high life expectancy is expected to continue. Both because of challenging environment of overseas market in fashion business and because of unusual current and future demographics in Japan, this paper aims to investigate, focused on the ladies fashion business market in Japan and seek for how to survive and develop in the future.

Keywords: Japanese ladies fashion business, customer satisfaction, commoditization
\end{abstract}




\section{Introduction}

Japan is a cutting edge fashion market that had sales valued at approximately $¥ 16.4$ trillion or US\$ 143 billion. Of this total, women's wear accounted for approximately 60 percent. Working women, who are fashion-conscious and have large disposable incomes, are some of the most important customers for fashion companies. Contemporary fashion, which contains the essence of the latest world's fashion trends, has good potential in the market. Japan is open to imported apparel and doesn't have significant tariff or non-tariff barriers to imported clothing. Clothing distribution channels in Japan have simplified in recent years but to succeed here a company needs good business practices such as timely, dependable communication and on-time shipping, etc. In recent years, the Japanese ladies fashion performs not so well domestically and overseas compared to other industries.

On the other hand, the latest population estimate by the Health, Labor and Welfare Ministry, released late last month, points to the accelerating decline of Japan's population with ever fewer births. The number of babies born in this country in 2018 is estimated at 921,000 - down 25,000 from the previous year and falling short of 1 million for the third year in a row. The lowest annual number of births on record since the government began taking comparable statistics in 1899 was outnumbered by 1.36 million deaths - a postwar record - thereby resulting in a record decline in the population - 448,000 people - for the 12th year-on-year fall in a row.

The Abe administration has vowed to tackle this national crisis by taking steps to support young couples in raising children, such as making preschool education free. However, the statistics indicate that it will be extremely hard to alter the demographic trend anytime soon. While those steps should be steadily taken over the long term, the government also needs to introduce policies geared toward the reality that the aging and shrinking of the population will continue.

Both the poor performance of the Japanese ladies fashion and the aging society in Japan lead its companies to the serious situation. On top, among Japanese consumers has been popular fast fashion that is a contemporary term used by fashion retailers for designs that move from catwalk quickly to capture current fashion trends afflicts Japanese apparel companies during the decade 1 . The purpose of this paper is set to investigate the current situation of Japanese ladies fashion and explore the countermeasure of how to recover from the predicament in response to the aging consumer power.

\section{Outlook}

Ladies fashion industry

Japan is a huge fashion market that offers great potential for foreign apparel manufacturers and designers. Contemporary women's wear, especially products made from high quality fabrics, one-of-a-kind items and clothing with great details have good potential in Japan. By contrast, affordable clothing like fast fashion items are also a viable player in Japan. Given the size of the market, it is highly competitive. To succeed, a company's product must be perceived as value to prices. The Japan Textiles Importer's Association (JTIA) discussed some unique characteristics of the Japanese market in their report entitled The Japanese women's wear market is a highly sophisticated consumer's market and to succeed, suppliers must be prepared to supply small lots with short delivery cycles.

\section{Aging society in Japan}

The number of annual births in Japan hit a record 2.69 million in 1949 during the postwar baby boom. When the second baby-boomer generation 2 was born in the early 1970s, the number still topped 2 million each year. But then it began to decline - dipping below 1.5 million in 
1984, 1.1 million in 2005 and 1 million in 2016. The total fertility rate, the estimated number of children a woman gives birth to in her lifetime, fell below 2.07 - the level deemed necessary to maintain a population - in the mid-1970s and has never recovered that threshold. The decline in the fertility rate has been attributed to a combination of various factors: changing lifestyles, more people marrying later in life or not marrying at all, the economic insecurity of younger generations in recent decades, which leave couples balking at having more than one child or any kids at all, and so on. The health ministry notes that after the second baby-boomer generation passed their mid-40s, the number of women of primary child-bearing age declined significantly.

\section{Data Description}

The survey was conducted on internet by ASMARQ Co., Ltd., a research firm in Japan from 18th to 20th October 2016. The number of its collected answers is 300 samples whose gender is female. As profiles of data (gender, aging ranges, resident area, marital status, occupation), the following statistic are included; the amount of monthly disposal income, the frequency of purchasing clothing, the amount of annual payment to clothing, the ladies items each surveyee purchase, etc. Figure 1 shows surveyees' age ranges and disposal income. The range from 60 to 65 accounts for 170 (56.7\%) and from 60 to up to 70 for 263 (87.7\%). The mode of disposal income is $¥ 25,000$ per month, followed by $¥ 15,000$ and $¥ 7,500$.
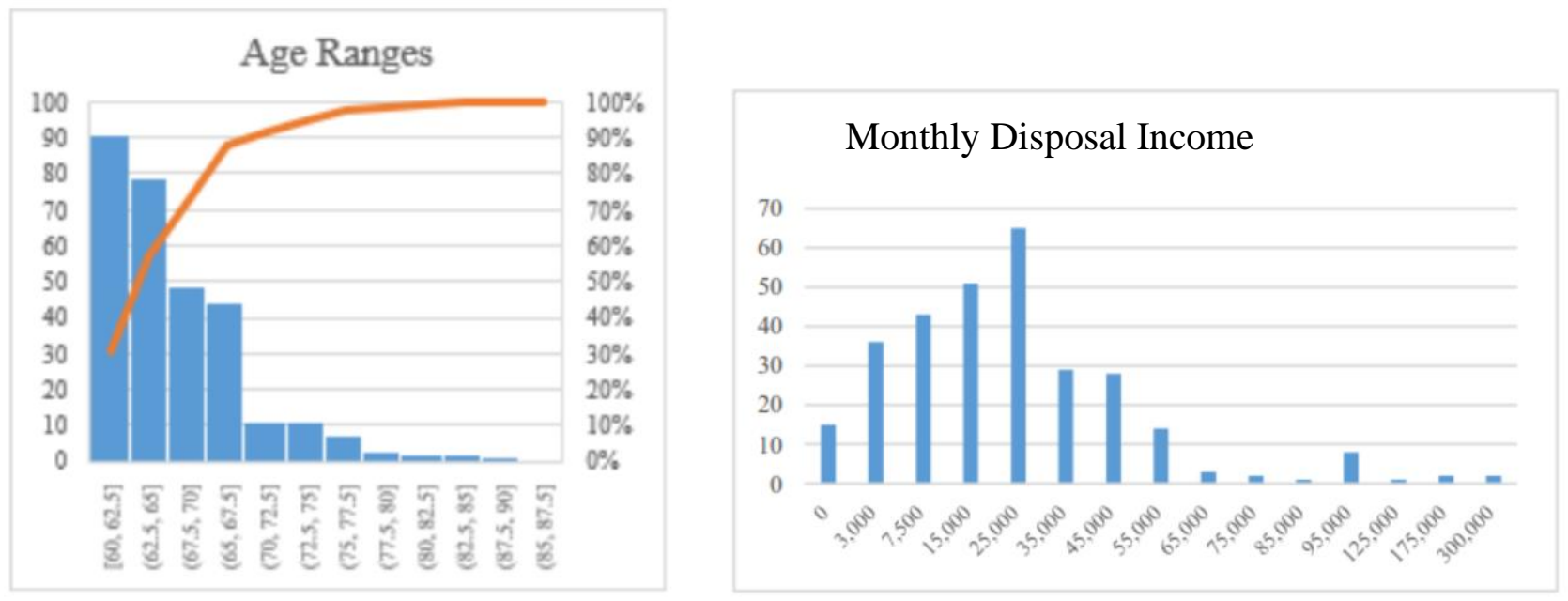

Figure 1. Basic Statistics (Age ranges \& Disposal Income)

\section{Methodologies}

First of all, the data collected are analyzed to investigate which variable has positive or negative correlation with another variable with the degree of statistical significance. This analysis is carried out with correlation analysis. Second, the collected samples are catabolized into several groups on the basis of cluster analysis algorithm to understand the objectives within the group is similar or related to one another and different or unrelated to the objects in other groups. Cluster analysis is widely used in market research when working with multivariate data from surveys and test panels. Market researchers use cluster analysis to partition the general population of consumers into market segments and to better understand the relationships between different groups of consumers/potential customers, and for use, this case, in market segmentation with the data of tourist profiles as well as buying behavior. A cluster analysis was conducted to order the data into distinguished groups. Third and lastly, the above two analysis results are taken into consideration to create a business model qualitatively as well as quantitatively. 


\section{Analysis}

First step is to analyze correlation among each variable. The method reveals one factor has great/little impact on another, and further analysis like parameter estimation can be feasible. In case it does not work well, relaunching another analysis (i.e. cluster analysis) is adopted in order to search out the relationship as well as each group's characteristics. 0102030405060 70 Monthky Disposal Income

\section{Correlation analysis}

Correlation analysis is a type of statistical analysis used to measure the strength or the degree of the relationship between two variables. Correlation analysis was deemed a valuable analysis for my research because it could shed some insight on the relationships between the variables that were determined to be those reflected from tourist buying behavior. For a correlation between variables $\mathrm{x}$ and $\mathrm{y}$, the formula for calculating the sample Pearson's correlation coefficient is given by:

$$
r_{x y}=\frac{\sum x_{i} y_{i}-n \bar{x} \bar{y}}{\sqrt{\left(\sum x_{i}^{2}-n \bar{x}^{2}\right)} \sqrt{\left(\sum y_{i}^{2}-n \bar{y}^{2}\right)}} .
$$

Where

- $\mathrm{n}$ is sample size

- xi, yi are the individual sample points indexed with $I$

$\bar{x}=\frac{1}{n} \sum_{i=1}^{n} x_{i}$ the sample mean; and analogously for $\bar{y}$

\section{Clustering analysis}

If the outcome of the correlation analysis provides a useful insight, cluster analysis will be manipulated with the data for the sake of achieving the research objective. Cluster analysis is widely used in market research when working with multivariate data from surveys and test panels. Market researchers use cluster analysis to partition the general population of consumers into market segments and to better understand the relationships between different groups of consumers/potential customers, and for use, this case, in market segmentation with the data of tourist profiles as well as buying behavior. A cluster analysis was conducted to order the data into distinguished groups. A complete linkage clustering method was utilized as demonstrated by the formula:

$$
\mathrm{d}(\mathrm{C} 1, \mathrm{C} 2)=\max \times 1 \in \mathrm{C} 1, \mathbf{x} 2 \in \mathrm{C} 2 \quad \mathrm{~d}(\mathbf{x} 1, \mathrm{x} 2)
$$

A non-hierarchical clustering method was employed and selected as the most appropriate for this data. This study like much other marketing research utilizes cluster analysis for segmentation of the 300 respondents. A non-hierarchical cluster analysis method was used to generate 5 clusters for further analysis. Another important use of cluster analysis is to gain insight into the characteristics and behaviour of homogeneous groups of customers within a sample. This use was important for gaining further insight into the characteristics of tourist to Japan and could prove the said research hypothesis with more depth.

\section{Results and Discussion}

Table 1 shows the results of correlation analysis with eight variables. The coefficients vary from minus 0.14 to 0.82 . The analysis moves on to Cronbach's alpha to estimate of the reliability of a psychometric test. The interpretation of a correlation coefficient depends on the context and purposes. Although a correlation of around 0.8 may be very low if one is verifying a physical law using high-quality instruments, it may be regarded as very high in the social 
sciences where there may be a greater contribution from complicating factors. There are four correlation outcomes that are located around 0.8. Accordingly, the outcomes have been tested as reliability with estimating Cronbach's alpha. The results are shown in Table 2.

Table 1. Results of Correlation Analysis

\begin{tabular}{|c|r|r|r|r|r|r|r|r|r|}
\hline & $\begin{array}{c}\text { Total amount } \\
\text { of purchasing } \\
\text { clothing }\end{array}$ & Age & $\begin{array}{c}\text { Disposal } \\
\text { income }\end{array}$ & $\begin{array}{c}\text { Frequency of } \\
\text { purchasing } \\
\text { clothing }\end{array}$ & $\begin{array}{c}\text { Long- } \\
\text { sleeve shirt }\end{array}$ & Jacket & Cut-saw & Sweater & Bottom \\
\hline $\begin{array}{c}\text { Total amount of purchasing } \\
\text { clothing }\end{array}$ & 1 & & & & & & & & \\
\hline Age & 0.32 & 1 & & & & & & & \\
\hline Disposal income & 0.38 & 0.62 & 1 & & & & & & \\
\hline Frequency of purchasing & 0.55 & 0.16 & 0.18 & 1 & & & & & \\
\hline clothing & 0.41 & 0.20 & 0.27 & 0.28 & 1 & & & & \\
\hline Long-sleeve shirt & 0.39 & 0.14 & 0.17 & 0.20 & 0.34 & & & & \\
\hline Jacket & 0.47 & 0.22 & 0.24 & 0.27 & 0.38 & 0.76 & & & \\
\hline Cut-saw & 0.45 & 0.18 & 0.21 & 0.26 & 0.34 & 0.82 & 0.82 & & 1 \\
\hline Sweater & 0.42 & 0.26 & 0.31 & 0.22 & 0.74 & 0.37 & 0.35 & 0.34 & \\
\hline Bottom & & & & & & & \\
\hline
\end{tabular}

Table 2. Results of Cronbach's Alpha

\begin{tabular}{|c|c|c|c|c|}
\hline & $\begin{array}{c}\text { Jacket \& } \\
\text { Cut-saw }\end{array}$ & $\begin{array}{c}\text { Jacket \& } \\
\text { Sweater }\end{array}$ & $\begin{array}{c}\text { Cut-saw \& } \\
\text { Sweater }\end{array}$ & $\begin{array}{c}\text { Long-sleeve shirt } \\
\text { \& Bottom }\end{array}$ \\
\hline $\mathrm{R}=$ & 0.76 & 0.82 & 0.82 & 0.74 \\
\hline Cronbach $\alpha=$ & 0.59 & 0.90 & 0.66 & 0.81 \\
\hline
\end{tabular}

As a result, on the basis of each alpha, the correlation between jacket and sweater and that of long-sleeve shirt and bottom reveal the appropriate degree of reliability due to higher cronbach's alphas. The fact can be made use of building a business model for activating the ladies apparel business. As a next step, the cluster analysis has been conducted into distinguished groups. A non-hierarchical clustering method was employed and selected as the most appropriate for this data. And was used to generate 5 clusters to gain insight into the characteristics and behavior of homogeneous groups of customers within a sample.

Table 3. Result of Cluster Analysis

\begin{tabular}{|r|r|r|r|r|r|r|r|r|r|r|l|}
\hline cluster & No. & $\begin{array}{c}\text { total } \\
\text { purchase } \\
\text { amount }\end{array}$ & age & $\begin{array}{c}\text { disposable } \\
\text { income }\end{array}$ & frequency & $\begin{array}{c}\text { long- } \\
\text { sleeve } \\
\text { shirt }\end{array}$ & jacket & cut-saw & sweater & bottoms & nickname \\
\hline 1 & 17 & 111,353 & 63.6 & 93,824 & 7.2 & 5,735 & 13,059 & 5,676 & 7,118 & 9,559 & active buyer \\
\hline 2 & 112 & 15,268 & 65.4 & 9,223 & 2.8 & 1,674 & 2,563 & 1,545 & 2,299 & 2,853 & mass \\
\hline 3 & 68 & 25,669 & 66.9 & 35,588 & 4.2 & 2,338 & 3,456 & 1,816 & 2,978 & 4,000 & laggards \\
\hline 4 & 69 & 64,130 & 64.4 & 27,696 & 7.1 & 3,130 & 5,667 & 2,855 & 4,275 & 5,790 & striver \\
\hline 5 & 10 & 300,000 & 63.8 & 76,000 & 12.7 & 6,550 & 25,500 & 9,350 & 29,000 & 10,650 & snazz \\
\hline
\end{tabular}

Table 3 indicates the results of cluster analysis into five categories. Cluster 1, named "active buyer" whose total purchase amount accounts for JPY111,353 totally, the second highest and their ages are the lowest among all. Cluster 2, called "mass," typically shows buying behavior. They spend less in apparel items and go shopping for clothing only 2.8 times annually. This is guessed due to the lowest disposal income, 9,223 JPY per month. 
Even though their average disposal income is relatively higher, the total purchase amount of Cluster 3 is only 25,669, the second lowest and so this cluster is called as "laggards." Cluster 4 is a group whose members are keen to apparel in spite of the second lowest disposal income. This cluster is possibly eligible to be a target market for retailers. Cluster 5 is more attractive in terms of business because their total purchase amount is 300,000 JPY per year with monthly disposal income of 76,000 JPY. The potential loyal customers belong to cluster 1, 4 and 5, that occupy $37.8 \%$ in total surveyees.

\section{CONCLUSION}

This paper aims to investigate, focused on the ladies fashion business market in Japan and seek for how to survive and develop in the future. Both the poor performance of the Japanese ladies fashion and the aging society in Japan lead its companies to the serious situation. The methodologies adopted two analysis, correlation analysis and cluster analysis. The result of the correlation analysis reveals there exist several coordination of apparel items that tend to be purchased together, increasing performance of retailers potentially. Another business strategy is to focus on specific groups. For example, in the analysis of clustering above is cluster 1, 4 and 5. The model for ladies apparel business in the aging society is recommended as following the concept of Marketing 4.0 that does not exclude traditional marketing activities; Marketing 1.0, 2.0 and 3.0. The concept of Marketing 4.0 is entirely covering marketing strategies as stated below.

When Marketing 1.0 was started, it was based on the product, since it develops all its strategies around it. Marketing 2.0 is responsible for developing strategies based on the consumer, is responsible for knowing them and satisfying their needs, reaching a specific segmentation of sex and age, as well as highlighting their feelings and the wide capacity for evaluating different products or services. Marketing 3.0 is based on the values of society, so it seeks to reinforce the integral image of the person and therefore create a better and balanced world, this is why companies start making public that they are socially responsible. It also seeks to improve the environment, retaking green marketing tends in order to reinforce products and campaigns, joining in this trend some of the most important brands around the globe. Marketing 4.0 is to 1) gain data-driven insight into the new ways customers are spending and the three driving subcultures: youth, women, and netizens; 2) examine firsthand examples of Marketing 4.0 boosting productivity by engaging customers at every touchpoint along their real-world paths through today's digital marketplace; 3) redefine customer engagement in the digital era, including human-centric marketing, creating customer conversations, and omnichannel strategies.

From the viewpoint of Marketing, the strategy for Japanese ladies apparel is said above, but in other points of view, interdisciplinary approaches are required to improve the performance like operational research, finance, accounting, informational communication technologies, etc.

\section{References}

Aging Population. Face challenges of a shrinking, aging population. The Japan Times, Jan 10 2019.

Cline, E. L. (2013). Overdressed: The shockingly high cost of cheap fashion. New York: Penguin Group.

Hines, T. (2001). From analogue to digital supply chains: implications for fashion marketing. Fashion Marketing: Contemporary Issues. Eds. T. Hines and M. Bruce. Oxford: Butterworth Heinemann, 26-47. 
Hines, T. (2004). Supply chain strategies: Customer driven and customer focused. Oxford: Elsevier.

Hines, T. (2007). Globalization: global markets and global supplies. In Hines, T. and M.Bruce. $2^{\text {nd }}$ Ed. Fashion Marketing Contemporary Issues, $2^{\text {nd }}$ Ed. Oxford: Elsevier.

Hines, T., \& Bruce, M. (2007). Fashion marketing: Contemporary issues. Amsterdam Boston: Butterworth-Heinemann. ISBN 9780080468174, OCLC 85017797, 2007.

Hobson, J. (2013). To die for? The health and safety of fast fashion. Occupational Medicine, 63(5),317-319.

House of Commons Environmental Audit Committee. (2019). Fixing fashion: Clothing consumption and sustainability. London: House of Commons. Retrieved 2019-03-12.

Japanese Fashion. Cool Japan. Retrieved from: https://www.jetro.go.jp/en/trends/fashion.html

Lowson, B., King, R., \& Hunter, A. (1999). Quick response: Managing the supply chain to meet consumer demand. Chichester: Wiley.

Muran, L. (2007). Profile of H\&M: A pioneer of fast fashion. Textile Outlook International, 7(4), 11-36.

Schlossberg, Tatiana (2019-09-03). How Fast Fashion Is Destroying the Planet. The New York Times. ISSN 0362-4331. Retrieved 2019-10-05.

Sunday Times Style, 17 September 2006.

Taplin, I. M. (2014). Who is to blame?: A re-examination of fast fashion after the 2013 factory disaster in Bangladesh. Critical perspectives on international business, 10(1-2), 72-83.

The Scoop: Understanding the Fashion Market in Japan. Retrieved from: WeConnectFashion, https://www.weconnectfashion.com/articles/the-scoop-understanding-the-fashion-mark et-in-japan. 
